\title{
Reinterpretação da potencialidade das Oficinas de Trabalho Crítico-emancipatórias
}

\author{
Reinterpretation of the potentiality of Critical-emancipative Workshops
}

Reinterpretación de la potencialidad de los Talleres de Trabajo Crítico-emancipatorios

\author{
Rosa Maria Godoy Serpa da Fonseca', Marta Araújo Amaral" \\ ' Universidade de São Paulo, Escola de Enfermagem, Departamento de Enfermagem em Saúde Coletiva. \\ São Paulo-SP, Brasil. \\ "Universidade Federal de Minas Gerais, Escola de Enfermagem, Departamento de Enfermagem Materno-Infantil. \\ Belo Horizonte-MG, Brasil.
}

Submissão: 19-03-2012 Aprovação: 05-11-2012

\begin{abstract}
RESUMO
Estudo qualitativo que teve como objetivo discutir a potencialidade das Oficinas de Trabalho Crítico-emancipatórias utilizando a dinâmica facilitadora da Árvore do Conhecimento. Os pilares teóricos constitutivos desta Oficina foram: a educação críticoemancipatória e o empoderamento; as emoções como construtoras do conhecimento; a abordagem dialética de transformação da realidade e da consciência; a participação e a responsabilidade compartilhada. O estudo foi realizado junto a 95 profissionais integrantes de 12 Equipes de Saúde da Família de um município do interior do Estado de São Paulo. Os resultados indicam que as potencialidades das Oficinas de Trabalho Crítico-emancipatórias relacionam-se diretamente aos seus pilares de sustentação e a dinâmica da Árvore do Conhecimento utilizada na avaliação mostrou-se potente para revelá-los. Assim, as Oficinas de Trabalho constituem uma importante ferramenta para a enfermagem no que tange à sua dimensão educativa, no caso, para o enfrentamento da violência de gênero contra a mulher.
\end{abstract}

Descritores: Educação em Saúde; Gênero; Avaliação Educacional; Empoderamento.

\begin{abstract}
This qualitative study aims to discuss the potential of Critical-emancipative Workshops utilizing the Tree of Knowledge as a facilitator strategy. The theoretical basis that constitutes this workshop was: the critical-emancipative education and empowerment; emotions as constructors of knowledge; the dialectical approach to transform reality and awareness; participation and shared responsibility. The study was conducted with 95 professionals working in 12 Family Health Staff in a city in the province of São Paulo, Brazil. The results indicate that the potential of the Critical-emancipatory Workshops relate directly to theoretical basis. The dynamics Tree of Knowledge used in the evaluation was powerful to reveal them. Thus, the workshops constitute an important tool for nursing in terms of their educational dimension, particularly, to face gender-based violence against women.
\end{abstract}

Key words: Health Education; Gender; Educational Evaluation; Empowerment.

\section{RESUMEN}

Este estudio cualitativo tiene como objetivo discutir el potencial de los Talleres Critico-emancipatorios utilizando la dinámica facilitadora del Árbol del Conocimiento. Los pilares teóricos que constituyen este taller fueron: la educación critica-emancipatoria y el empoderamiento, las emociones como constructoras del conocimiento, el enfoque dialéctico para transformar la realidad y la conciencia, la participación y la responsabilidad compartida. El estudio fué realizado con 95 profesionales que trabajan en 12 equipos de salud familiar en un municipio de la provincia de São Paulo, Brasil. Los resultados indican que el potencial de los Talleres Critico-emancipatorios se relaciona directamente con sus pilares de apoyo y la dinámica del árbol del conocimiento utilizado en la evaluación fue de gran alcance para revelarlos. Por lo tanto, los talleres constituyen una herramienta importante para enfermería en cuanto a su dimensión educativa, en este caso, para hacer frente a la violencia de género contra las mujeres. Palabras clave: Educación para la Salud; Género, Evaluación Educativa; Capacitación. 


\section{INTRODUÇÃO}

\section{As oficinas de trabalho crítico-emancipatórias na enfer-} magem

A história da enfermagem mostra um caminho árduo rumo à sua consolidação como profissão, marcada pelo fazer inerente à condição feminina de cuidar dos corpos, inserindo-os ou reinserindo-os no processo de reprodução social, de acordo com a ordem social vigente ou até mesmo, excepcionalmente, insurgindo-se contra ela. No entanto, dada talvez a marca indelével da vontade de ajudar o próximo, trazida desde a sua gênese como prática empírica até à enfermagem moderna com Florence Nigthingale - e até nossos dias - temos buscado qualificar e capacitar enfermeiras e demais trabalhadores para atuarem no conjunto das práticas de saúde de forma a garantir o bem estar e a saúde da população. Isto tem sido feito de várias formas, incluindo-se nelas as práticas participativas como modalidade crítico-emancipatória visando ao reconhecimento do sujeito social imbuído de possibilidade de transformar o mundo, na busca de melhores condições de vida e saúde.

Entre tais práticas, merecem destaque as chamadas Oficinas de Trabalho, surgidas no campo da educação, no movimento feminista, nos anos 1970, como tentativa de oferecer às mulheres um espaço de reflexão sobre a matriz feminina e as relações de gênero a partir de situações cotidianas vividas por elas próprias. Este movimento visava contribuir para o crescimento individual das mulheres e ao mesmo tempo trazer mudanças no âmbito coletivo. Foi uma estratégia largamente utilizada pelo Programa de Atenção Integral à Saúde da Mulher (PAISM) como carro-chefe das práticas educativas ${ }^{(1)}$. De lá para cá tem sido largamente utilizada para a população em geral e para a qualificação de trabalhadores.

Disseminou-se por diversas áreas, tentando articular subjetividade, racionalidade, experiência pessoal e conhecimento. Foi denominada grupo de autoconsciência, grupo de reflexão, oficina de trabalho, dentre outros. No Departamento de Enfermagem em Saúde Coletiva da EEUSP, a prática de Oficinas de Trabalho iniciou-se da década de 1990, como um espaço de reflexão, intervenção e empoderamento, nos programas interventivos voltados para a qualificação da força de trabalho (intervenção de enfermagem) e, logo após, para coleta de dados de investigações. Inúmeras experiências foram desenvolvidas, reforçando a contribuição desta prática para as duas vertentes do trabalho de enfermagem, ou seja, a intervenção educativa em grupos e a investigação, com resultados surpreendentes ${ }^{(2)}$.

A Oficina de Trabalho Crítico-emancipatória (OTC) é um espaço de construção coletiva grupal, cujo produto pode ser apropriado pelos participantes, posto que retrata a contribuição de cada um no conteúdo e na qualidade da sua participação. Caracteriza-se por um ambiente descontraído, facilitado pela utilização de práticas pedagógicas incentivadoras da integração e do estabelecimento de uma relação horizontal de poder entre participantes e coordenação. A síntese contém não só os posicionamentos e representações evidenciados durante as discussões como também novos conhecimentos, introduzidos pela coordenação ou por especialista.
Pode tratar-se de "uma prática de intervenção psicossocial, seja em contexto pedagógico, clínico comunitário ou de política social (...) um processo estruturado com grupos (...) sendo focalizado em torno de uma questão central que o grupo se propõe a elaborar, em um contexto social. A elaboração que se busca não se restringe a uma reflexão racional mas envolve os sujeitos de maneira integral, formas de pensar, sentir e agir"(3).

Os seus pilares de sustentação estão fundados na educação crítico-emancipatória( ${ }^{(4)}$ e na consequente noção de empoderamento $^{(5)}$ - vindo daí seu nome; no uso das emoções como construtoras do conhecimento ${ }^{(6)}$; na abordagem dialética do movimento da consciência, nas noções de participação e responsabilidade compartilhada.

Como método de intervenção, segue os pressupostos e etapas da Teoria de Intervenção Práxica da Enfermagem em Saúde Coletiva(7) que propõe uma forma sistematizada para captar, interpretar e intervir nas práticas educativas, tendo em vista as dimensões do singular, particular e estrutural. A dimensão singular, relativa aos processos de ensino e avaliação, é aquela em que, em última instância, são operacionalizados os referenciais pedagógicos da dimensão particular que levam o sujeito a integrar-se ao sistema em que vive, com resultados previsíveis sobre sua conduta posterior. Ambas articulam-se aos processos de produção e reprodução social da coletividade na qual se inserem, historicamente determinado, que constitui a dimensão estrutural. À captação, interpretação e intervenção, segue-se a contínua reinterpretação do fenômeno, de forma práxica, constituindo a unidade dialética teoria-prática.

A despeito da comprovação empírica dessa alternativa privilegiada para a intervenção educativa, sua potencialidade encontra-se ainda pouco explorada no sentido de constituir comprovadamente elementos sobre os quais é possível construir e trocar o conhecimento. Diante disto, pergunta-se: qual é a real potencialidade da oficina como transformadora do conhecimento individual e grupal, tanto no que se refere aos temas como também às possibilidades de reconhecimento do humano nas relações que se estabelecem entre participantes e entre estes e a coordenação? Quais são as possibilidades de transformação no que tange a forma e conteúdo das práticas educativas que podem ser evidenciadas no contexto da realização de uma Oficina?

Tendo isto em vista, os objetivos deste trabalho foram: conhecer a potencialidade da OTC como transformadora do conhecimento, no contexto da violência de gênero e desvelar as possibilidades de reconhecimento do humano nas relações que se estabelecem entre os todos os participantes; articular as potencialidades referidas aos pilares de sustentação, desvelando as possibilidades de transformação dos sujeitos por meio desta prática educativa.

\section{METODOLOGIA}

O objeto de estudo foi a avaliação de uma OTC realizada junto a trabalhadores das equipes da Estratégia Saúde da Família (ESF) de um Município do interior do Estado de São Paulo, que recebeu a denominação de Mulher e violência: reconstruindo a assistência no âmbito do PSF. As finalidades 
dessa Oficina foram reconstruir a assistência à mulher em situação de violência prestada pelas equipes da ESF e obter subsídios para a introdução de um protocolo de atendimento à saúde para mulheres em situação de violência sexual. Tal finalidade foi alcançada por meio dos objetivos: estimular a reflexão acerca da violência contra as mulheres como problema de saúde, determinado pela construção social das matrizes femininas e masculinas em relação, na sociedade brasileira; analisar criticamente a assistência à saúde prestada pela ESF às mulheres em situação de violência, em especial, de violência sexual; preparar os profissionais para detectarem situações de vulnerabilidade à violência contra as mulheres e prestarem assistência compatível com suas necessidades.

Quanto aos procedimentos metodológicos, participaram seis enfermeiras e 89 agentes comunitários de saúde. A duração foi de três sessões de quatro horas cada, em dois dias consecutivos. Na primeira sessão foi feita uma reflexão sobre a construção social da masculinidade e da feminilidade e as relações de gênero. As sessões seguintes referiram-se especificamente à violência de gênero iniciando-se com uma reflexão acerca da sua determinação social e das práticas de saúde empregadas para o seu enfrentamento. As estratégias: reflexão individual e grupal, facilitadas por meio de elaboração de esculturas com papéis, massa de modelar, painéis com recortes de revistas, sucatas e brinquedos. A dramatização foi também utilizada como recurso pedagógico por excelência para estimular a reflexão acerca da violência contra as mulheres com base na realidade. Foram dramatizados casos relatados pelos participantes e conhecidos pela maioria do grupo. Ao final de cada sessão, era feita uma avaliação parcial por meio de uma palavra ou gesto que demonstrasse o que cada participante tinha achado da Oficina naquele momento. Ao final foi feita uma avaliação geral por meio da estratégia da Árvore do Conhecimento, objeto deste artigo.

A Árvore do Conhecimento foi utilizada como estratégia facilitadora abrangendo processo e produto. Trata-se de uma estrutura formada por um tronco e galhos que sustentam outros elementos a serem colocados pelos participantes, a partir da sua representação acerca do conhecimento construído. Os elementos que compõem a árvore e o ambiente onde ela está podem incluir raiz, adubo, sol, chuva, minhoca, semente, flores, inseticida, folhas, frutos, flores, raio, trovão, nuvem e outros, à escolha das pessoas. Além dos elementos disponibilizados pela coordenação, os participantes podem incluir ou criar outros.

Os sujeitos são convidados a fazer uma reflexão individual acerca do conhecimento adquirido ou construído durante a Oficina enquanto escolhem o que é colocado na árvore. O importante é que os elementos representem o que cada pessoa pensa e sente a respeito do trabalho realizado. Esta estratégia é usada visando estimular a criatividade e facilitar a exposição dos posicionamentos e sentimento, de maneira que abranjam tanto os aspectos considerados positivos, facilitadores e importantes para a transformação da prática cotidiana, como aqueles que dificultaram ou impossibilitaram a construção coletiva do conhecimento.

A árvore pode ser construída com tronco e galhos naturais, folhas, flores, frutos ou elaborada com papel, recortes de tecidos, contas, massa de modelar, barbante, fios, linhas, botões e outros, colocados à disposição dos participantes. $\mathrm{O}$ importante é que sejam disponibilizados materiais que estimulem a criatividade, podendo-se permitir também que os participantes busquem fora do ambiente da Oficina o que quiserem incluir. Numa outra oficina, realizada com docentes de enfermagem num ambiente rural, uma das participantes fez questão de ir buscar e colocar delicadamente uma minhoca viva aos pés da árvore, falando acerca da sua importância para a aeração do solo e de seus conhecimentos acerca do tema em debate $A$ categoria gênero na investigação de enfermagem.

Realizada a reflexão individual, os participantes são convidados a permanecer em círculo ao redor do tronco e dos galhos, falando um por vez acerca dos elementos escolhidos e do que representam, na medida em que os colocam na árvore. Ao final, é feita uma síntese, de acordo com as categorias empíricas que se conformam a partir dos conteúdos das falas.

\section{Coleta, tratamento e análise dos dados}

Neste estudo, a coleta de dados foi feita mediante gravação e transcrição das falas dos cerca de 95 participantes dos três grupos de agentes comunitários de saúde das 12 equipes de Saúde da Família do Município, durante a construção e descrição da árvore. Foi solicitado que falassem livremente sobre o conteúdo e a forma da oficina. As falas individuais foram analisadas através da análise de conteúdo ${ }^{(8)}$.

O referencial teórico-metodológico foi constituído pelos pilares nos quais se assentam a OTC formulada e estruturada pelo Grupo de Pesquisa "Gênero, saúde e enfermagem, do Departamento de Enfermagem da Escola de Enfermagem da Universidade de São Paulo, cadastrado no Diretório de Grupos de Pesquisa do CNPq. Tais pilares ensejaram as seguintes categorias analíticas: educação emancipatória, empoderamento, abordagem dialética do movimento da consciência, participação e responsabilidade compartilhada.

\section{Procedimentos éticos}

O estudo integrou o projeto Práticas profissionais e violência contra as mulheres: um recorte de gênero e classe social que teve o protocolo de pesquisa aprovado pelo Comitê de Ética em Pesquisa da Escola de Enfermagem da Universidade de São Paulo (Processo 517/2005/CEP-EEUSP). Foram observados todos os aspectos éticos envolvidos na pesquisa com seres humanos, da Resolução 196 de 10 de outubro de 1996, do Conselho Nacional de Saúde. Antes do início das atividades, foi claramente explicitado aos participantes os objetivos e a forma de coleta. Foi enfatizada a voluntariedade e liberdade na decisão em participar da pesquisa, de modo que, àqueles que concordaram, foi solicitada a leitura e assinatura do Termo de Consentimento Livre e Esclarecido.

\section{RESULTADOS}

Iniciando a sessão de avaliação foi feita a retomada das expectativas dos participantes captadas na primeira sessão. A dinâmica utilizada havia sido a construção do "Jardim dos Desejos". Os participantes escreviam em folhas de papel sulfite 
colorido o que esperavam da Oficina. Posteriormente, as folhas eram embaralhadas e lidas, antes de serem amassadas e servirem de matéria prima para a confecção de flores que foram coladas em uma parede, em espaço próprio. O Jardim foi mantido intacto durante todas as sessões da Oficina. Esta dinâmica possibilitou conhecer o grupo, posto que o fato das frases serem lidas por pessoas diferentes das que as escreveram, facilitou o entrosamento. Tal fato foi percebido pelas brincadeiras, comentários e outras formas de comunicação verificadas.

As expectativas relacionadas ao conteúdo eram: qualificar-se para ajudar a clientela a resolver as questões relacionadas à violência de gênero; adquirir conhecimentos para repassá-los a outras pessoas, clientes ou trabalhadores de saúde; aprender a cuidar levando em conta as diferenças; melhorar a prática e incrementar o saber utilizado no cotidiano do trabaIho dos Agentes Comunitários de Saúde; aprender a aplicar o conhecimento adquirido no dia a dia e como conscientizar as mulheres sobre a violência e maneiras de enfrentá-la; receber orientações sobre onde, quando e para onde encaminhar muIheres vítimas de violência e que adquirissem mais segurança para lidar com tais situações no seu cotidiano.

Com relação à forma, esperavam que a aprendizagem se desse de maneira não maçante, atrativa e prazerosa gerando reflexões que contribuíssem para a melhoria do trabalho desenvolvido pelas equipes de saúde; aprender a trabalhar com dinâmicas facilitadoras, que o ambiente fosse propício à troca de experiências e que a oficina fosse interessante.

A retomada das expectativas no momento da avaliação final foi crucial para situar os participantes na historicidade do processo. A seguir, foram retomados o conteúdo e as estratégias pedagógicas utilizadas no desenvolvimento da Oficina. Ao final, ressaltou-se que o produto consistia no conhecimento construído coletivamente e no processo desenvolvido durante as sessões e que, naquele momento, eram estes os objetos da avaliação. A análise de conteúdo das falas possibilitou a emergência de categorias empíricas que se configuraram como expressões da materialidade dos pilares de sustentação da OTC.

\section{A. А ОTC como possibilidade de ampliar e repassar o conhecimento}

Para vários participantes, a OTC encerra grande possibilidade de aquisição de conhecimentos que entendem não como sendo exclusivamente seus mas que desejam e têm o dever de repassá-los a outros trabalhadores e à clientela, em especial, às mulheres.

A chuva, o adubo e as flores representam os conhecimentos que eu adquiri e o fruto que é o resultado do que eu consegui hoje aqui e o que eu vou passar para a frente.

A flor pra mim significa como eu cheguei aqui tentando dar frutos, mas precisando de alguma coisa. Na oficina eu aprendi muitas coisas que posso passar pra frente. Agora posso levar o fruto que nasceu dessa flor.

Eu escolhi a nuvem representando as dúvidas que nós tínhamos no começo a respeito da violência contra a mulher.
(...) o fruto seria o que nós vamos colher no futuro para estar passando o que nós aprendemos prá comunidade.

\section{B. A OTC como possibilidade de crescimento e transfor- mação pessoal}

Nesta categoria, foram incluídas as falas que se referiam à Oficina como início de um movimento e, a partir dele, a ampliação do conhecimento e as possibilidades de transformações pessoais e da prática profissional. As transformações da natureza foram relacionadas às transformações pessoais ocorridas durante a Oficina.

Eu escolhi o fruto porque hoje eu sou o fruto, porque, as minhas expectativas foram totalmente superadas. O que eu queria, eu aprendi, consegui entender. Então eu escolhi o fruto, porque, ontem à tarde eu era apenas uma semente, hoje de manhã eu fui flor, hoje já sou fruto. (palmas)

Eu escolhi a semente, a chuva, o adubo e o sol porque eu acho que mostra a gente fazendo essa oficina. Nós temos isso aqui representando: a semente, porque foi plantada alguma coisa boa em nós, o adubo para que isso não pare por aí, a chuva para a gente continuar regando e continuar fazendo com que essa oficina cresça para que o Brasil todo tenha isso. Escolhi o sol também porque sem ele nada tem vida.

\section{A OTC como possibilidade de transformação da prática e de ampliação do compromisso para com a clientela.}

Foi marcante a OTC tida como espaço para desenvolvimento de potencialidades em direção à transformação da prática, representada pelo adubo, pela flor que antecede o fruto e assim por diante. Desta forma, amplia-se também o compromisso para com a clientela.

Eu escolhi o adubo porque acho que não adianta implantar um programa e não aperfeiçoar. Eu acho que o adubo seria o aperfeiçoamento, isto que tivemos aqui...

Eu escolhi o adubo porque, assim como a árvore, preciso de adubo para ser forte, bonita, eu acho que a gente também precisa ter muito conhecimento para poder ajudar a população e é o que nós tivemos aqui, muito conhecimento.

Eu peguei a flor porque eu acho também que é uma flor muito bonita e eu cheguei aqui para adquirir conhecimentos e poder estar lidando na comunidade.

Além de possibilitar a transformação da prática, na visão de alguns participantes, a OTC pode reforçar o seu compromisso com a população, pois se trata de um espaço que propiciou mudança da visão de mundo deles em relação ao problema da violência contra as mulheres. Algumas falas, carregadas de emoção e idealizando a visão de mulher podem ser interpretadas como forma de potencializar a possibilidade de mudança propiciada por um trabalho diferenciado na área da saúde. 
Eu escolhi a flor porque ela é muito delicada e a mulher tem que ser tratada assim com delicadeza (risos e palmas) (...) eu aprendi bastante a ver tudo de um jeito diferente, até as mulheres que a gente atende.

Bom, eu escolhi a flor. Eu aprendi que independente da situação que a mulher está vivendo, seja ela mesmo de violência sexual, a gente tem que passar para ela o lugar ao sol. Tudo pode mudar e elas têm que acreditar. Eu acredito!

\section{A OTC como forma diferente de aprender}

Os participantes foram unânimes em afirmar que a modalidade de Oficina propiciou um ambiente de aprendizagem alegre, descontraído, agregador, além de fértil.

A flor por ser de duas cores bem alegres, foi o que a gente esperava da oficina, foi bem descontraída, não maçante ...

Já participei de muitos cursos, é sempre quase a mesma coisa, mas aqui encontrei coisas diferentes (...) folhas simbolizando as parcerias.

Fazia muito tempo que eu não participava de um curso assim. O pessoal fala, fala, fala e nada. Aqui não, a gente falou, brincou, conheci pessoas que eu não conhecia, revi quem eu conhecia e foi muito bom.

\section{E. A OTC como esperança de mudar a própria situação,} como forma de empoderamento

A oficina revelou-se como espaço de enfrentamento e superação, em outras palavras, de empoderamento. Os depoimentos a seguir, repletos de emoção, retratam o desafio que as mulheres enfrentam ao lidar com a violência tanto como mulheres quanto como profissionais.

Eu escolhi o trovão porque eu acho a violência um trovão na vida de uma mulher, na minha é. É um desastre e o raio está junto aqui. Tem também a nuvem porque a muIher às vezes, fica vedada quando ela sofre uma violência, ela não consegue encontrar saída, não consegue ver nada. Esta nuvem é aquela nuvem negra, não aquela nuvem azul bonita. Mas, em contrapartida a gente tem que ter sempre esperança e esta Oficina me deu esperança de continuar.

Escolhi a minhoca porque sem ela a terra não vai sobreviver, se não tiver oxigenação. E quem leva essa oxigenação para terra são as minhocas. Eu saio dessa Oficina oxigenada...

É a flor, porque apesar de toda a violência, mulher é mulher e é flor e esta oficina provou isso. Porque apesar de tudo, todo mundo consegue sempre voltar e ser inteiro. Pode demorar, pode ser doído mas, querendo, a gente consegue ser flor novamente. Acho muito importante que a gente passe isso para todos: para a comunidade, para nossas crianças, que daqui pra frente isto seja um ponto de referência para todos nós. Foi maravilhoso... (choro e palmas)
Essa vivência me fez ver e eu sinto que estou saindo daqui como um sol, com a esperança de que apesar das tempestades, dos altos e baixos a gente tem que ter uma perspectiva de melhora, de luz. Se a gente se imbuir de estar se melhorando, tudo vai melhorar. (...) Acho que a gente pode tentar modificar tudo para melhor, para se sentir mais segura, mais firme com propósitos melhores, de ser feliz, que é o propósito do ser humano. Porque nós temos a obrigação de ser feliz! (choro e palmas)

\section{F. A OTC sob o olhar da equipe coordenadora}

Seguindo-se à avaliação dos participantes, a equipe coordenadora também registrou suas impressões sobre a Oficina. Os maiores destaques foram as possibilidades de aprendizagem e a troca de conhecimentos e experiências. A mobilização e integração da equipe foram tamanhas que até mesmo o trabalhador de apoio técnico que, ao mesmo tempo era o motorista a serviço das docentes, espontaneamente, emitiu sua avaliação. Cabe ressaltar que ele esteve voluntariamente presente a toda a oficina, envolvendo-se nas atividades mesmo sem participar diretamente delas.

Eu vou por aqui essa flor, essa flor amarela, pelo carinho que tive aqui e por tudo isso que vocês ensinaram prá mim aqui. Estou sem palavras porque tenho muitas palavras para falar. Muito obrigado... (palmas)

As docentes também fizeram suas falas, pontuando a satisfação do trabalho realizado e o conhecimento adquirido e compartilhado.

Eu escolho toda essa árvore, a árvore do conhecimento, que é o conhecimento que eu adquiri com vocês todos, (...) aprendi muito e é com cada um de vocês que a gente aprende. (palmas)

Aprendi muito e gosto muito disso porque é uma delícia ser um eterno aprendiz. Eu vou abolir da música aquela parte que fala da "dor de ser um eterno aprendiz" e vou ficar só com a delícia de ser um eterno aprendiz. Eu não vou colocar nada na árvore, eu vou fazer uma foto e vou levar a árvore comigo. Eu vou levar a imagem dela porque recordar é viver e eu quero reviver muitas vezes estes momentos que passamos aqui juntos. Assim eu levo vocês comigo, porque cada vez que eu olhar pra árvore, eu vou me lembrar de vocês e vai ser bem gostoso outra vez. Obrigada por tudo. (palmas)

\section{DISCUSSÃO}

A análise das categorias, de uma maneira geral, revelou que os pilares de sustentação da OTC estiveram presentes e foram reconhecidos pelos participantes. Os princípios da educação crítico-emancipatória ${ }^{(4)}$ puderam ser detectados quando foram explicitadas as potencialidades do método especialmente como possibilidade de ampliação dos próprios conhecimentos, transformação dos sujeitos e das práticas, de maneira que possam ser reconhecidos como efetivos transformadores da 
realidade, imbuídos de politicidade e com potência para agir de maneira a auxiliar as mulheres a resolverem suas questões relacionadas à violência de gênero. A perspectiva educativa da Oficina evidenciou-se fortemente quando os participantes revelaram que suas próprias experiências favoreceram a reflexão e a ampliação dos conhecimentos, por meio de uma forma diferente de aprender.

Sabe-se que o conhecimento se dá por sucessivas aproximações e reflexões sobre a realidade. Pode ser definido como "o esforço do 'espírito' para compreender a realidade objetiva, dando-lhe um sentido, uma significação, mediante o estabelecimento de nexos aptos a satisfazerem as exigências intrínsecas de sua subjetividade"(9), não podendo existir fora da sociedade que produz tais consciências.

Assim, se o ato de conhecer se respalda na prática social, o sujeito deste conhecimento, produto destas relações sociais, não é um indivíduo isolado, mas um sujeito social. A Oficina com a troca de experiências e conhecimentos constitui um elemento privilegiado para ampliação do conhecimento, tanto quanto para a sua transmissão.

A função social da educação é a transmissão desses conhecimentos para que o educando possa interagir na sociedade, instrumentalizando-se para transformá-la. Neste sentido, não basta ao ser humano criar o conhecimento, mas transmiti-lo no processo de reprodução social.

O ato de produzir conhecimento não é obra de uma consciência singular, mas uma das formas de prática social, prática que tem como sujeito os homens articulados entre si por relações sociais. Esta concepção de conhecimento, como processo de produção social e de um sujeito coletivo, demarca e orienta a tarefa no campo da aprendizagem ${ }^{(10)}$.

A aprendizagem se dá num movimento dialético entre o ser humano e a realidade objetiva que é objetiva por existir fora da consciência humana. Neste processo ele capta, transforma e devolve à realidade o conhecimento, agora sob sua ação, modificando os elementos que o rodeiam. O processo é contínuo e dinâmico, com duplo sentido de direção, o educando se transforma e transforma a realidade da qual participa. Neste sentido, a educação só se dá como prática transformadora quando se pauta em conhecimentos que ampliam a visão sobre a realidade que não é alguma coisa isolada do ser humano, mas o conjunto das relações sociais no qual ele vive e atua, conforme um dos pressupostos de condução da OTC. Produzir o conhecimento

é um ato político (...): enseja a explicitação dos desejos e das vontades, canalizados para a construção da cidadania solidária e digna. Não há cidadania e dignidade na produção de conhecimento (...), sem o correspondente valor de solidariedade, autonomia, emancipação e liberdade: não do ser individual, mas do ser que coletiva e socialmente produz a vida...(11)

O empoderamento, advindo da educação crítico-emancipatória, esteve presente quando as pessoas referiram-se ao conhecimento adquirido como forma de transformação de si, de sua prática e da sua visão de mundo acerca da violência contra as mulheres. Da mesma maneira, esperavam qualificar-se para ajudá-las e ajudarem-se a ter uma vida melhor e mais digna. Tal empoderamento está diretamente relacionado ao desenvolvimento de programas que promovam nas comunidades uma consciência crítica sobre sua realidade vivida ${ }^{(12)}$.

O pilar de sustentação referente às emoções como construtoras do conhecimento também pode ser verificado não só por meio das falas como das emoções, em especial o riso, a raiva, a dor e os aplausos que as acompanhavam. Tal pilar pode ser detectado durante as sessões, de igual maneira, mas apareceu claramente explicitado na avaliação inclusive quando a Oficina foi tida como um espaço onde as pessoas sentiram-se bem, acolhidas, confortadas e até mesmo cuidadas. A palavra emoção vem do latim emovere, onde o 'e- (variante de ex-) significa 'fora' e movere significa 'movimento', ou seja, a emoção é a única expressão externa do que se sente internamente. Embora pareçam sinônimos, emoção e sentimento possuem distinções conceituais. Enquanto a emoção é a expressão externa de um movimento interno e a única que tem prerrogativa de ocorrer inconscientemente, o sentimento é a experiência subjetiva da emoção. Enquanto a emoção pode se manifestar independente de qualquer ação alheia ou sua própria, o sentimento prevê sensação, possível em decorrência de um estímulo. Por isso, não seria errôneo afirmar que o sentimento pode ocorrer como uma conseqüência da emoção, sendo, portanto, dela derivado ${ }^{(13)}$. Cabe salientar que

aquilo que identificamos como emoção é uma abstração conceitual de um complexo processo de atividade humana que também envolve o agir, o sentir e o avaliar. O modo proposto de construção teórica demonstra a necessidade simultânea e a interdependência de faculdades que nossa cultura abstraiu e separou umas das outras: emoção e razão, avaliação e percepção, observação e ação. O modelo de conhecimento sugerido é anti-hierárquico e antifundamentalista e pode ser adequadamente simbolizado pela radical metáfora feminista de espiral ascendente. As emoções não são mais básicas que a observação, a razão ou a ação para a construção da teoria, mas também não são menos importantes. Cada uma dessas faculdades reflete um aspecto do conhecimento humano, inseparável dos outros. Assim, (...) o desenvolvimento de cada uma dessas faculdades é uma condição necessária para o desenvolvimento de todas ${ }^{(6)}$.

A abordagem dialética do movimento da consciência ficou evidente quando foi avaliado positivamente o uso da dramatização como estratégia para a reflexão sobre a prática e as possibilidades de transformação da realidade no âmbito da ESF. $\mathrm{O}$ fato de terem sido utilizados casos conhecidos favoreceu a ampliação da análise e das possibilidades de intervenção para além da escuta e dos encaminhamentos até então realizados. A dialética é

a grande ideia fundamental segundo a qual o mundo não deve ser considerado como um complexo de coisas acabadas, mas como um complexo de processos em que as 
coisas, na aparência estáveis, do mesmo modo que os seus reflexos intelectuais no nosso cérebro, as ideias, passam por uma mudança ininterrupta de devir e decadência em que, finalmente, apesar de todos os insucessos aparentes e retrocessos momentâneos, um desenvolvimento progressivo acaba por se fazer hoje $\mathrm{i}^{(14)}$.

Assim a OTC, construída num ir e vir, da realidade à abstração, possibilitou transformações pessoais, tanto nos participantes como na equipe coordenadora, confirmando que ao transformar o mundo, o ser humano transforma-se a si mes$\mathrm{mo}^{(15)}$. A participação e a responsabilidade compartilhada foram detectadas por meio de falas referentes ao ambiente em que se deram os trabalhos e na representação dos participantes acerca do espaço. Foram enfáticos ao pontuar as relações cordiais, a possibilidade de sentirem-se presentes, explicitando inclusive diferenças entre este método e estratégias pedagógicas anteriormente vivenciadas.

Esta e outras experiências anteriores de Oficinas de Trabalho conduzidas por nós mostraram que a grande diferença entre as oficinas e outras práticas educativas é a não superficialidade do trabalho, o aprofundamento de questões ligadas à realidade, o convite para conhecer a si mesmo, além de possibilitar o encadeamento de novos trabalhos que visem ao crescimento individual e coletivo ${ }^{(16-17)}$.

Outro dado interessante que diz respeito à participação e responsabilidade compartilhada, foi que a partir do vínculo estabelecido entre os participantes e o consequente respeito pelas opiniões e posicionamentos apresentados, pode-se observar uma mudança de comportamento do grupo em relação ao compromisso com o coletivo. Neste caso específico, tratando-se de um tema bastante complexo como é o da violência contra as mulheres, o grupo inclusive acolheu e mostrou-se solidário às mulheres do próprio grupo que revelaram vivenciar o problema. Refletindo sobre ele coletivamente, as mulheres Agentes Comunitárias de Saúde puderam, ao mesmo tempo em que se instrumentalizavam para atender a clientela, refletir sobre a própria vida, vislumbrando e fortalecendo estratégias de enfrentamento.

A violência contra a mulher pode ser explicada como um fenômeno que se constitui a partir da naturalização da desigualdade entre os sexos, que se assenta nas categorias hierárquicas, historicamente construídas, como um dos mecanismos ideológicos capaz de legitimar o status quo, entre os quais se encontram as classificações sociais e, aqui, a classificação baseada nas diferenças entre os sexos. Essa classificação permite a sujeição das mulheres nas relações de gênero, desqualificando-as como insuperavelmente inferiores, porque biologicamente diferentes ${ }^{(18)}$.

Assim, para se fortalecer e encontrar estratégias de enfrentamento, é imprescindível que as mulheres desenvolvam sua autonomia, consequência direta do empoderamento. "Por autonomia entende-se a capacidade e as condições concretas que permitem às mulheres tomar livremente as decisões que afetam as suas vidas e o poder de agir segundo tais decisões." ${ }^{\prime(18)}$

Na medida em que a OTC propicia a ampliação da consciência de homens e mulheres sobre o dito, mostra-se como uma possibilidade de libertar as mulheres do cárcere da violência. Sim, porque, autonomia, do ponto de vista da filosofia, "conduz o pensamento à ideia de liberdade, da propriedade pela qual o ser humano pretende poder escolher as leis que regem sua conduta, ou seja, dá possibilidade e capacidade de livre decisão dos indivíduos e grupos sobre suas próprias ações na vida."(19)

\section{CONCLUSÃO}

A experiência da utilização da árvore do conhecimento para avaliar a OTC mostrou-se compatível com a necessidade de conhecer suas potencialidades, com base nos pilares teóricos definidos da educação crítico-emancipatória, as emoções como construtoras do conhecimento e a participação. Destes, decorrem outros, não menos importantes como o empoderamento e a responsabilidade compartilhada.

Além de ressaltar tais pressupostos, as falas dos participantes referiram-se às relações interpessoais construídas e fortalecidas durante a OTC, conferindo-lhe um estatuto de prática educativa associada à arte de criar o conhecimento. Isto se revela na dimensão estética da Enfermagem, pois que advém do preparo cuidadoso, meticuloso, de uma relação de amor entre o artista e sua obra. Quando a vê realizada, processa-se nele algo que vai muito além da razão confirmando que "a Enfermagem é uma arte; e para realizá-la como arte, requer uma devoção tão exclusiva, um preparo tão rigoroso, quanto a obra de qualquer pintor ou escultor; pois o que é tratar da tela morta ou do frio mármore comparado ao tratar do corpo vivo (...)? É uma das artes; poder-se-ia dizer, a mais bela das artes!"(20)

\section{REFERÊNCIAS}

1. Ministério da Saúde. Assistência integral à saúde da muIher: bases de ação programática. Brasília: Centro de Documentação, Ministério da Saúde. Brasília, 1984.

2. Fonseca RMGS; Guedes RN; Zalaf MRR; Venâncio KCMP Pesquisa de gênero na produção de enfermagem: contribuição do Grupo de Pesquisa Gênero, Saúde e Enfermagem da EEUSP. Rev Esc Enferm USP 2011;45(n. esp.):1691-6.

3. Afonso MLM. Oficinas em Dinâmica de Grupo: um método de intervenção psicossocial. São Paulo: Casa do Psicólogo; 2006. p. 9-63.

4. Freire P. Pedagogia da Autonomia: saberes necessários à prática educativa. 24. ed. São Paulo: Paz e Terra; 2002.

5. Wallestein N. Empowerment education applied to youth. In: Matiella AC The multicultural challenge in health education. Santa Cruz, Califórnia: ETR Associates Publishers; 1994. p. $153-76$. 
6. Jaggar AM. Amor e conhecimento: a emoção na epistemologia feminista. In: Jaggar AM; Bordo SR. Gênero, corpo, conhecimento. Rio de Janeiro: Rosa dos Tempos; 1997. p. $157-85$

7. Egry EY. Saúde coletiva: construindo um novo método para a enfermagem. São Paulo: Ícone; 1996.

8. Minayo MCS. O desafio do conhecimento: pesquisa qualitativa em saúde. 8. ed. São Paulo: Hucitec; 2004.

9. Severino AJ. Filosofia. 2. ed. São Paulo: Cortez Editora; 2007.

10. Freire $\mathrm{P}$, Rivière $\mathrm{P}$. O processo educativo segundo Paulo Freire e Pichon Rivière. São Paulo: Vozes; 1987.

11. Egry EY. O tsunami, a solidariedade e a construção social do conhecimento em enfermagem. Rev Esc Enferm USP 2011;45(4):799-801.

12. Pereira ALF As tendências pedagógicas e a prática educativa nas ciências da saúde. Cad Saúde Pública 2003;19(5):1527-34.

13. França M. Emoções e sentimentos. [artigo na internet]. [acesso em 23 de fevereiro de 2012]. Disponível em
$<$ http://www.artigonal.com/auto-ajuda-artigos/emocoes-e-sentimentos-5138574.html>

14. Engels apud Politzer G. Princípios Elementares de Filosofia. 3. ed. São Paulo: Centauro; 2007.

15. Marx K, Engels F. A ideologia alemã. São Paulo: Boitempo; 2007.

16. Melo VP; Gandra LRL; Amaral MA; Fonseca RMGS. Adolescência, sexualidade e gênero: possibilidades das oficinas de trabalho crítico-emancipatórias. REME 12:390-5.

17. Amaral MA; Fonseca RMGS. Entre o desejo e o medo: as representações sociais das adolescentes acerca da iniciação sexual. Rev Esc Enferm USP 2006;40(3):469-76.

18. Guedes RN; Fonseca RMGS. A autonomia como necessidade estruturante para o enfrentamento da violência de gênero. Rev Esc Enferm USP 2011;45(n. ${ }^{\circ}$ esp.):1733-7.

19. Lalande A. Vocabulário técnico e crítico da filosofia. 3. ed. São Paulo: Martins Fontes; 1999.

20. Nightingale F. Notas sobre Enfermagem: o que é e o que não é. São Paulo: Cortez, ABEn-CEPEn; 1989. 